\title{
Acetaminophen-cysteine adducts during therapeutic dosing and following overdose
}

Kennon J Heard ${ }^{1,2^{*}}$, Jody L Green ${ }^{1,3}$, Laura P James ${ }^{4}$, Bryan S Judge ${ }^{5}$, Liza Zolot ${ }^{1}$, Sean Rhyee ${ }^{6}$, Richard C Dart ${ }^{1,2}$

\begin{abstract}
Background: Acetaminophen-cysteine adducts (APAP-CYS) are a specific biomarker of acetaminophen exposure. APAP-CYS concentrations have been described in the setting of acute overdose, and a concentration $>1.1 \mathrm{nmol} / \mathrm{ml}$ has been suggested as a marker of hepatic injury from acetaminophen overdose in patients with an ALT >1000 IU/ L. However, the concentrations of APAP-CYS during therapeutic dosing, in cases of acetaminophen toxicity from repeated dosing and in cases of hepatic injury from non-acetaminophen hepatotoxins have not been well characterized. The objective of this study is to describe APAP-CYS concentrations in these clinical settings as well as to further characterize the concentrations observed following acetaminophen overdose.
\end{abstract}

Methods: Samples were collected during three clinical trials in which subjects received $4 \mathrm{~g} /$ day of acetaminophen and during an observational study of acetaminophen overdose patients. Trial 1 consisted of non-drinkers who received APAP for 10 days, Trial 2 consisted of moderate drinkers dosed for 10 days and Trial 3 included subjects who chronically abuse alcohol dosed for 5 days. Patients in the observational study were categorized by type of acetaminophen exposure (single or repeated). Serum APAP-CYS was measured using high pressure liquid chromatography with electrochemical detection.

Results: Trial 1 included 144 samples from 24 subjects; Trial 2 included 182 samples from 91 subjects and Trial 3 included 200 samples from 40 subjects. In addition, we collected samples from 19 subjects with acute acetaminophen ingestion, 7 subjects with repeated acetaminophen exposure and 4 subjects who ingested another hepatotoxin. The mean (SD) peak APAP-CYS concentrations for the Trials were: Trial 1- $0.4(0.20) \mathrm{nmol} / \mathrm{ml}$, Trial 2$0.1(0.09) \mathrm{nmol} / \mathrm{ml}$ and Trial 3- $0.3(0.12) \mathrm{nmol} / \mathrm{ml}$. APAP-CYS concentrations varied substantially among the patients with acetaminophen toxicity $(0.10$ to $27.3 \mathrm{nmol} / \mathrm{ml})$. No subject had detectable APAP-CYS following exposure to a non-acetaminophen hepatotoxin.

Conclusions: Lower concentrations of APAP-CYS are detectable after exposure to therapeutic doses of acetaminophen and higher concentrations are detected after acute acetaminophen overdose and in patients with acetaminophen toxicity following repeated exposure.

\section{Background}

Acetaminophen toxicity is a major cause of acute liver failure in the United States. While many cases have a clear history of acetaminophen exposure, there are a substantial number of cases in which the cause of liver injury is not clear. As serum acetaminophen concentrations may be undetectable by the time the patient has acute liver failure, there is a need for a biomarker with a longer detection time.

\footnotetext{
* Correspondence: kennon.heard@rmpdc.org

${ }^{1}$ Rocky Mountain Poison and Drug Center, Denver Health, Denver CO, USA
} Full list of author information is available at the end of the article
The metabolism of acetaminophen by CYP2E1 forms $N$-acetyl-p-benzoquinone imine (NAPQI), a reactive metabolite that binds to cysteine residues in cellular proteins and forms acetaminophen protein adducts, herein referred to acetaminophen-cysteine (APAP-CYS) [1]. Previous experimental work has shown that APAPCYS is formed within hepatocytes and released into the circulation following cell necrosis in the setting of acute acetaminophen toxicity $[2,3]$. This product is detectable in serum for several days following acute overdose, and it has been proposed that detection of APAP-CYS is diagnostic of acetaminophen toxicity [4]. The majority of the studies measuring APAP-CYS have included

\section{() Biomed Central}


patients with known or suspected acute overdose of acetaminophen [4-7].

While studies of patients with acetaminophen-induced liver injury can determine the sensitivity of the assay, the performance of the assay cannot be studied solely in this population. For a diagnostic study to be valid, the assay should be evaluated in patients who have similar diseases to the diagnosis of interest. Therefore, in this study, the assay was tested in other patient groups including patients with liver injury from other causes, patients taking therapeutic doses of acetaminophen and patients with liver injury following repeated ingestion of supratherapeutic doses of acetaminophen. The objective of this study is to describe the serum concentrations of APAP-CYS measured under five conditions: 1) during therapeutic dosing, 2) in patients with suspected acetaminophen toxicity from repeated overdosing, 3) following acute acetaminophen overdose with early acetylcysteine treatment, 4) following acute acetaminophen overdose with delayed acetylcysteine treatment and 5) following ingestion of non-acetaminophen hepatotoxins.

\section{Methods}

This report describes the analysis of samples collected in two settings: 1) during three clinical trials that included an acetaminophen treatment arm and 2) an observational study of patients with an overdose of acetaminophen or another hepatotoxin. The three clinical trials was separately reviewed and approved by the Colorado Multiple Institutional Review Board. Trial 3 was also approved by the Center For Addition and Mental Health Research Ethics Board. The observational study was approved by the Colorado Multiple Institutional Review Board and the Spectrum Health Research and Human Rights Committee. All subjects provided informed consent for inclusion in the trials and in the observational study.

\section{Study methods for clinical trials}

The populations, duration of dosing and days of sampling for all trials are shown in Table 1. The clinical trials were performed to evaluate the effect of acetaminophen on serum transaminase activity. In all clinical trials, healthy adult subjects older than 21 years were administered the maximum daily dose of acetaminophen (4 g/day) or placebo (only Trials 2 and 3 had a placebo arm). The study subjects were non-drinkers (Trial 1-Registration number NCT 00616018) [8], moderate drinkers (Trial 2 Registration number NCT 004000621) [9] and subjects who chronically abuse alcohol (Trial 3- Registration number NCT 00427206) [10]. For Trial 2, moderate drinking was defined as 1-3 alcoholic beverages per day. For Trial 3, subjects who chronically abuse alcohol were identified at an inpatient detoxification facility; the average duration of their
Table 1 Characteristics and peak recorded serum APAPCYS concentrations for subjects administered $4 \mathrm{~g} /$ day of acetaminophen during three clinical trials

\begin{tabular}{|c|c|c|c|}
\hline & Study & & \\
\hline & Trial 1 & Trial 2 & Trial 3 \\
\hline Subjects & Non-drinkers & $\begin{array}{l}\text { Moderate } \\
\text { drinkers }\end{array}$ & Alcoholics \\
\hline Duration of dosing & $10 \mathrm{~d}$ & $10 \mathrm{~d}$ & $5 \mathrm{~d}$ \\
\hline Days of sampling & $\begin{array}{l}0,4,7,9 \\
11,14\end{array}$ & 0,11 & $0,2,4,6,7$ \\
\hline$n$ & 24 & $\begin{array}{l}91 \text { APAP } \\
47 \text { placebo }\end{array}$ & $\begin{array}{l}40 \text { APAP/ } \\
7 \text { placebo }\end{array}$ \\
\hline Median age (range) years & 34.5 (23 to 63$)$ & 30 (21 to 64) & 46 (33 to 66) \\
\hline Male & 7 (29\%) & $47(52 \%)$ & $39(98 \%)$ \\
\hline \multicolumn{4}{|l|}{$\mathrm{ALT}$} \\
\hline $\begin{array}{l}\text { Baseline ALT } \\
\text { Median (Range) IU/L }\end{array}$ & $24(14$ to 45$)$ & $19(11$ to 49$)$ & $\begin{array}{l}29(10 \text { to } \\
178)\end{array}$ \\
\hline $\begin{array}{l}\text { Peak ALT } \\
\text { Median (Range) IU/L }\end{array}$ & 45 (19 to 136$)$ & $\begin{array}{l}25(14 \text { to } \\
128)\end{array}$ & $\begin{array}{l}47.5(8 \text { to } \\
238)\end{array}$ \\
\hline $\begin{array}{l}\text { ALT > ULN during } \\
\text { study } n(\%)\end{array}$ & $14(58 \%)$ & $17(19 \%)$ & $24(60 \%)$ \\
\hline \multicolumn{4}{|l|}{ Peak Serum APAP-CYS } \\
\hline Mean (SD) nmol/L & $0.4(0.20)$ & $0.1(0.09)^{*}$ & $0.3(0.12)$ \\
\hline Range $\mathrm{nmol} / \mathrm{L}$ & 0.1 to 1.0 & 0.0 to 0.5 & 0.1 to 0.8 \\
\hline
\end{tabular}

Trial 1 included non-drinkers treated for 10 days, Trial 2 included moderate drinkers treated for 10 days and Trial 3 included alcoholic subjects treated for five days. APAP-CYS-Acetaminophen-cysteine adducts, ALT-alanine aminotransferase, ULN-upper limits of normal for the test. SD-standard deviation.

${ }^{*} \mathrm{p}<0.001$ vs Trial 1 and 3 .

current drinking binge was longer than 1 month. Subjects in Trials 1 and 3 could not consume ethanol during the study; subjects in Trial 2 were instructed to continue their usual drinking pattern during the study (an average of 1-3 drinks/day). The first acetaminophen or placebo dose was administered on study day 1 in all trials.

\section{Study methods for observational study}

In the observational study, patients were enrolled by two medical toxicology services evaluating patients for known or suspected acetaminophen overdose. The following patients were eligible for enrollment: 1) patients following acute acetaminophen ingestion (defined as a single ingestion or multiple ingestions occurring within an 8 hour period), 2) patients with repeated acetaminophen ingestions (defined as multiple ingestions over a period of greater than 8 hours); 3) patients that may have ingested a product that may produce hepatotoxicity (other than acetaminophen). A trained investigator collected a structured data set for each patient subject including demographics, time course of ingestion, 
co-ingestions (including ethanol), medical history (including history of alcohol abuse and liver disease) and clinical course (including time of acetylcysteine treatment relative to the overdose, laboratory variables and outcome). Samples for APAP-CYS quantification were collected during routine blood draws, and therefore sample collection was not systematically timed. In this report we refer to the highest recorded determination as the peak value, but we recognize that our nonsystematic sampling scheme may miss the true peak values.

The patients in the overdose cohort were stratified into the following four groups: 1) Acute acetaminophen ingestion who received acetylcysteine within 8 hours (acute early treatment), 2) acute acetaminophen ingestion who received acetylcysteine after 8 hours (acute late treatment), 3) repeated acetaminophen ingestion and 4) ingestion of a hepatotoxin without acetaminophen.

\section{Sample Preparation, APAP-CYS Protein Adduct Assay}

Serum samples were frozen at each institution and stored at $-80^{\circ} \mathrm{C}$ until analysis. Samples were analyzed using a previously described method [6]. The samples were processed with gel filtration, protein digestion and the resulting APAP-CYS concentration was determined by high pressure liquid chromatography using electrochemical detection. The limit of detection of the assay is $0.03 \mathrm{uM}$ (micromolar) based on the lowest quality control concentration measured with a CV of within $15 \%$. The final concentrations are reported as nmol of APAP$\mathrm{CYS} / \mathrm{ml}$ of serum to be consistent with previous publications.

\section{Analysis plan}

For both the trials and the observational study, categorical variables are described as percentages with 95\% exact binomial confidence intervals. Continuous variables that were non-skewed are reported using means with standard deviations while continuous variables with skewed distributions are described using medians with inter-quartile ranges. The mean peak adduct concentrations for the three therapeutic trials were compared using ANOVA with a protected Fisher's Least Significant Difference to adjust for multiple comparisons in post hoc tests. An overall, 2-sided p-value $<0.05$ was considered significant. The relationship of peak APAPCYS concentrations to peak ALT for each trial was evaluated with Spearman's rho. If the 95\% confidence intervals for rho included zero, we considered there to be no significant relationship between peak recorded ALT and peak recorded APAP-CYS. Calculations were performed using SAS version 9.2 (Carey, NC) and correlations were performed using Prism 5.0 (GraphPad Software, San Diego CA).

\section{Results}

\section{Clinical trials}

There were 144 samples from 24 subjects in Trial 1, 276 samples from 91 APAP and 47 placebo subjects in Trial 2, and 200 samples from 40 APAP and 7 placebo subjects in Trial 3. The demographics and peak recorded APAP-CYS concentrations in trial subjects are shown in Table 1.

At baseline, no subjects in Trial 1, 6 subjects in Trial 2 ( 2 acetaminophen, 4 placebo) and 5 subjects ( 1 placebo, 4 APAP) in Trial 3 had detectable APAP-CYS concentrations. Of these 11 APAP-CYS baseline positive subjects, 4 reported acetaminophen use in the 4 days preceding the study and had detectable APAP serum concentrations at baseline, 3 reported use in the 4 days preceding the study but did not have a detectable serum APAP concentration at baseline, 1 subject denied acetaminophen use, but had a detectable APAP concentration at baseline and 3 subjects denied acetaminophen ingestion and had no detectable acetaminophen at baseline.

All acetaminophen-treated subjects $(n=115)$ in the Trials 1 and 3 had detectable APAP-CYS in one or more samples. Eighty five of 91 APAP-treated subjects in Trial 2 had detectable serum concentrations of APAP-CYS on day 11 of the trial. Thus, overall, APAPCYS was detected in the vast majority of samples obtained from the APAP-treated arms of the 3 trials. The mean peak recorded adduct concentrations in Trial 2 were lower than concentrations measured in Trials 1 and 3 ( $\mathrm{p}<0.001$, values shown in Table 1$)$. However, there was substantial overlap of individual subject values between the trials and these differences are unlikely to be of clinical significance (Figure 1).

Two placebo treated subjects in Trial 2 and 1 placebo treated subject in Trial 3 had detectable APAP-CYS at

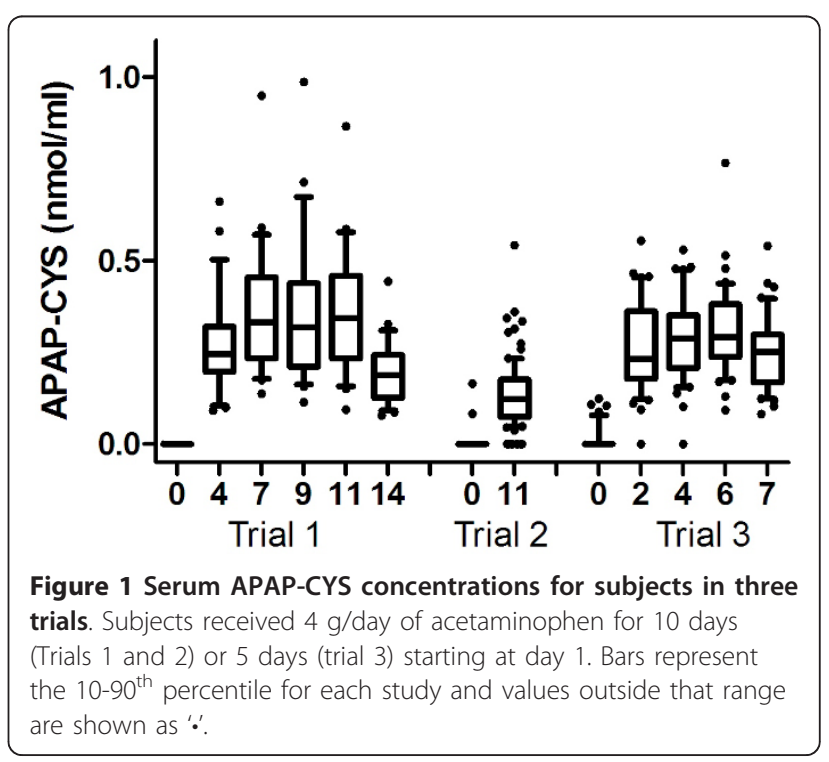


the end of the study. All of these subjects had detectable APAP-CYS concentrations $(0.03,0.16,0.17 \mathrm{nmol} / \mathrm{ml})$ at baseline and the final concentrations $(0.004,0.06$, $0.09 \mathrm{nmol} / \mathrm{ml}$ respectively) were lower than the baseline concentrations.

Mean APAP-CYS concentrations tended to increase during the dosing period of each study (Figure 1). In Trial 1, samples were collected 1 and 4 days after the final acetaminophen dose and in Trial 3 samples were collected 1 and 3 days after the final acetaminophen dose. In both of these trials, the APAP-CYS concentrations 1 day after dosing was stopped were similar to the concentrations measured during dosing, and samples obtained 3 or 4 days after stopping acetaminophen were lower than those observed on dosing (Figure 1).

Peak recorded APAP-CYS concentrations and peak recorded ALT for all subjects receiving therapeutic doses are shown in Figure 2. Please note that peak recorded values of APAP-CYS and ALT did not necessarily occur at the same time point so the values reported in Figure 2. The Spearman's rho correlation (with 95\% CI) of the relationship between ALT and APAP-CYS for all trials was not significant: Trial 10.40 ( -0.37 to 0.44$)$; Trial 20.23 (-0.02 to 0.41$)$ and Trial 30.14 ( -0.18 to 0.43$)$.

\section{Observational study}

Thirty five patients were enrolled in the observational study; this included 31 acetaminophen overdoses and 4 subjects who had ingested another hepatotoxin. No serum samples were obtained for APAP-CYS analysis in 4 patients (all acetaminophen), so these patients were excluded. Note that the subject numbers shown in the tables and figures are non-consecutive because packets were pre-numbered; missing numbers reflect unused packets rather than exclude subjects. Among the remaining patients, the types of acetaminophen

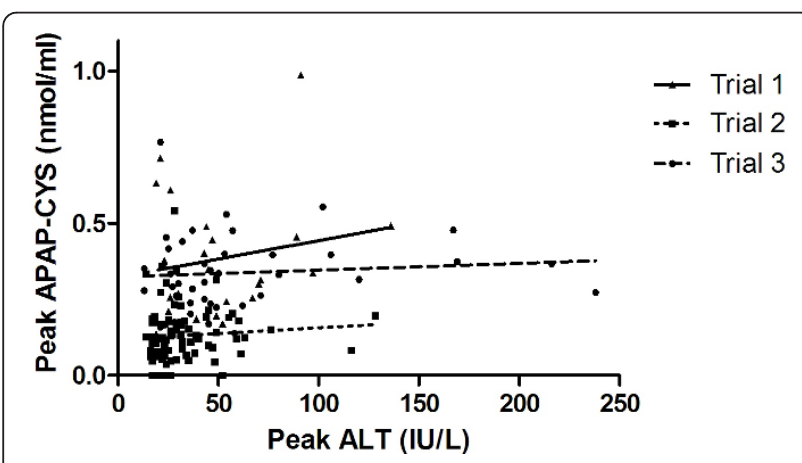

Figure 2 Peak APAP-CYS concentration by peak ALT during three trials where subjects were administered $4 \mathrm{~g}$ /day of acetaminophen. ingestion were: 12 acute early treatments (within 8 hours of exposure), 7 acute late treatments (more than 8 hours post exposure), 7 repeated ingestions and 1 unknown. This analysis included a total of 82 samples for APAP-CYS measurement. The number of samples for each patient ranged from 1 to 5 . All of the patients who reported ingesting acetaminophen had detectable serum APAP-CYS and none of the 4 patients who reported ingesting hepatotoxins without acetaminophen had APAP-CYS detected (Table 2). Figures 3, 4, and 5 show the time course of serum APAP-CYS concentrations and ALT activity for selected patients in the acetaminophen overdose group who had three or more measurements. The figures are segregated by time to treatment with NAC (early, Figure 3 ), $>8$ hour (Figure 4), and by patients with supratherapeutic acetaminophen ingestions (Figure 5).

As the values for both ALT and APAP-CYS were highly skewed in the overdose and toxicity patients, the values were $\log$ transformed for analysis. A plot of the $\log$ of adduct concentrations versus log of ALT is shown in Figures 6. Please note that peak recorded values of APAP-CYS and ALT did not necessarily occur at the same time point so the values reported in Figure 6 . There was a modest Spearman correlation between the peak recorded adducts and peak recorded ALT ( $\mathrm{rho}=0.68$, 95\% CI 0.36 to 0.85 ).

\section{Discussion}

Our study results demonstrate that low concentrations of APAP-CYS are detectable in serum following therapeutic dosing with acetaminophen in the vast majority of subjects. The peak recorded APAP-CYS concentrations are higher in non-drinkers and abstaining subjects who chronically abuse alcohol than in moderate drinkers, but the differences were small. The APAP-CYS concentrations following acetaminophen overdose varied widely. Serum APAP-CYS concentrations in patients with hepatic injury following acetaminophen overdose were generally much higher than those observed during therapeutic dosing. However, three overdose subjects (Subjects SH-05, SH-06, DH-06 in Figure 5) with normal serum ALT activity or minimal ALT elevation (due to early treatment with $\mathrm{N}$-acetylcysteine or late sampling during resolution of injury) had APAP-CYS concentrations that were of the same order of magnitude as those observed with therapeutic dosing.

A previous report showed measureable APAP-CYS concentrations with therapeutic dosing [11]. Based on earlier published data in animal models, and early in the development of this assay, APAP-CYS formation was thought to occur only after acetaminophen overdose with hepatic injury $[12,13]$. However, as the sensitivity 
Table 2 Demographics and clinical characteristics of patients enrolled following acute overdose, repeated overdose or after ingestion of a non-acetaminophen hepatotoxin

\begin{tabular}{|c|c|c|c|}
\hline $\begin{array}{l}\text { Patient } \\
\text { number }\end{array}$ & $\begin{array}{l}\text { Age/ } \\
\text { Sex }\end{array}$ & $\begin{array}{l}\text { Peak ALT IU/ } \\
\text { L }\end{array}$ & Case description \\
\hline & & & Acute acetaminophen treated within 8 hours of ingestion \\
\hline D-01 & $26 \mathrm{~F}$ & 37 & 40 unknown strength tabs. $4.5 \mathrm{hr}$ [APAP] $230 \mathrm{mcg} / \mathrm{ml} .6 .5 \mathrm{hrs}$ to NAC. \\
\hline D-02 & $20 \mathrm{~F}$ & 18 & 20 g. 2.5 hr [APAP] 262 mcg/ml. 5 hr to NAC. \\
\hline D-04 & $35 \mathrm{~F}$ & 26 & 10-13 g. 6 hr [APAP] $177 \mathrm{mcg} / \mathrm{ml} .7 \mathrm{hr}$ to NAC. \\
\hline D-06 & $20 \mathrm{~F}$ & 17 & Approx 30 tabs unknown strength. 4 hr [APAP] 319 mcg/ml. 6 hr to NAC. \\
\hline $\mathrm{SH}-03$ & $55 \mathrm{~F}$ & 16 & 10.4 g. 4 hr [APAP] 184 mcg/ml. 6 hr to NAC. \\
\hline $\mathrm{SH}-04$ & $22 \mathrm{M}$ & 9903 & 25 g. 5 hr [APAP] 221 mcg/ml. 7 hr to NAC. \\
\hline $\mathrm{SH}-05$ & $38 \mathrm{~F}$ & 57 & 39 g. $13 \mathrm{hr}$ [APAP] $296 \mathrm{mcg} / \mathrm{ml} .3 .5 \mathrm{hr}$ to NAC. \\
\hline $\mathrm{SH}-06$ & $16 \mathrm{~F}$ & 14 & "3 handfuls" of unknown product. 4 hr [APAP] $293 \mathrm{mcg} / \mathrm{ml}$. $5.5 \mathrm{Hr}$ to NAC. \\
\hline $\mathrm{SH}-07$ & $24 \mathrm{M}$ & 27 & 13-16.5 g. 6 hr [APAP] 235 mcg/ml. 8 hr to NAC. \\
\hline $\mathrm{SH}-12$ & $42 \mathrm{M}$ & 30 & Unknown amount. $4 \mathrm{hr}$ [APAP] $215 \mathrm{mcg} / \mathrm{ml} .7 \mathrm{hr}$ to NAC. \\
\hline $\mathrm{UCH}-05$ & $27 \mathrm{~F}$ & 1729 & $48 \mathrm{gm} .1 \mathrm{hr}$ [APAP] $557 \mathrm{mcg} / \mathrm{ml} .5 .5 \mathrm{hr}$ to NAC. \\
\hline \multirow[t]{2}{*}{$\mathrm{UCH}-06$} & $51 \mathrm{~F}$ & 22 & $19.5-53$ g. 3 hr [APAP] $467 \mathrm{mcg} / \mathrm{ml} .5 \mathrm{hr}$ to NAC. \\
\hline & & & Acute acetaminophen treated more than 8 hours post ingestion \\
\hline D-05 & $25 \mathrm{~F}$ & 18 & Unknown amount. 8 hr [APAP] 373 mcg/ml. 9 hr to NAC. \\
\hline D-07 & $38 \mathrm{M}$ & 8880 & 7 g. 41 hr [APAP] 9 mcg/ml. 49 hr to NAC. Hep C. \\
\hline D-08 & $37 \mathrm{~F}$ & 1999 & $5 \mathrm{~g} \times 28 \mathrm{hrs}$ apart. $12 \mathrm{hr}$ (from first ingestion) [APAP] $121 \mathrm{mcg} / \mathrm{ml} .13 \mathrm{hr}$ to NAC. \\
\hline $\mathrm{SH}-08$ & $37 \mathrm{~F}$ & 1362 & 13-16 g. $10 \mathrm{hr}$ [APAP] $89 \mathrm{mcg} / \mathrm{ml}$. Time to NAC $15 \mathrm{hr}$. \\
\hline $\mathrm{UCH}-01$ & $52 \mathrm{~F}$ & 457 & 15-25 g. 24 hr [APAP] 10 mcg/ml. Time to NAC 26 hr. \\
\hline $\mathrm{UCH}-07$ & $40 \mathrm{~F}$ & 2083 & Unknown amt. $27 \mathrm{hr}$ [APAP] $336 \mathrm{mcg} / \mathrm{ml}$. Time to NAC $28 \mathrm{hr}$. \\
\hline \multirow[t]{2}{*}{$\mathrm{UCH}-14$} & $41 \mathrm{~F}$ & 4372 & 30 g. $36 \mathrm{hr}$ [APAP] $5.6 \mathrm{mcg} / \mathrm{ml}$. Time to NAC $36 \mathrm{hr}$. \\
\hline & & & Repeated acetaminophen ingestion \\
\hline D-00 & $27 \mathrm{M}$ & 741 & Approximately $10 \mathrm{~g} /$ day for $4 \mathrm{~d}$ for dental pain. Presenting [APAP] $0 \mathrm{mcg} / \mathrm{ml}$. \\
\hline$\overline{D-18}$ & $17 \mathrm{M}$ & 229 & $\begin{array}{l}\text { Approximately } 4 \mathrm{~g} / \text { day for } 2 \mathrm{~d} \text { then } 8 \mathrm{~g} / \text { day for } 1 \text { day for prevertebral abscess. Presenting [APAP] } \\
20 \mathrm{mcg} / \mathrm{ml} \text {. }\end{array}$ \\
\hline D-19 & $44 \mathrm{~F}$ & 2862 & 4-6 g/day for 4 days then 25-50 g OD. $60 \mathrm{hr}$ [APAP] $0 \mathrm{mcg} / \mathrm{ml}$. NAC $14.5 \mathrm{hr}$ post OD. \\
\hline $\mathrm{UCH}-03$ & $28 \mathrm{~F}$ & 3189 & 2-3 tabs unknown str every 2-4 hrs for $7 \mathrm{~d}$. Presenting [APAP] $16 \mathrm{mcg} / \mathrm{ml}$. \\
\hline $\mathrm{UCH}-08$ & $29 \mathrm{~F}$ & 2099 & Approx $12 \mathrm{gm}$ over 14 hrs. Presenting [APAP] 0 mcg/ml. \\
\hline $\mathrm{UCH}-09$ & $38 \mathrm{~F}$ & 284 & $21 \mathrm{~g}$ over $5 \mathrm{~d}$. Presenting [APAP] 0 mcg/ml. CMV hepatitis on liver biopsy. \\
\hline \multirow[t]{2}{*}{$\mathrm{UCH}-11$} & $24 \mathrm{M}$ & 7979 & 5-7.5 g/day for $4 \mathrm{~d}$. presenting [APAP] $0 \mathrm{mcg} / \mathrm{ml}$. \\
\hline & & & Acetaminophen ingestion-not able to determine time course \\
\hline \multirow[t]{2}{*}{$\mathrm{UCH}-15$} & $29 \mathrm{~F}$ & 131 & Unknown amt over several hours. Presenting [APAP] 36 mcg/ml. Polypharmacy OD. \\
\hline & & & Ingestion of other hepatotoxins \\
\hline D-16 & $12 \mathrm{M}$ & 2346 & Isoniazd-induced liver injury during therapeutic use. \\
\hline $\mathrm{SH}-01$ & $47 \mathrm{M}$ & 174 & $1500 \mathrm{mg}$ of tramadol. Alcoholic \\
\hline $\mathrm{SH}-02$ & $24 \mathrm{M}$ & 18 & $9.5 \mathrm{~g}$ of valproic acid. \\
\hline $\mathrm{SH}-09$ & $18 \mathrm{~F}$ & 18 & $8 \mathrm{~g}$ phenytoin. \\
\hline
\end{tabular}

[APAP]- serum acetaminophen concentration, NAC- acetylcysteine, ALT- alanine aminotransferase.

of the assay has improved $[6,14]$, it is clear that that APAP-CYS formation occurs in the setting of low dose exposure associated without ALT activity [11].

An unexpected finding was that APAP-CYS concentrations were lower at study day 11 in Trial 2 than the end of study samples collected for the subjects in Trial 1 (study day 11) and Trial 3 (study day 7). No adducts were detected in six of the 91 APAP dosed patients on study day 11 in Trial 2. Slight differences in the sampling scheme among these three studies make direct comparisons difficult. It is possible that these differences are due to variations in sample timing, handling or processing or non-compliance with study medication. However, overall compliance with dosing in Trial 2 was 

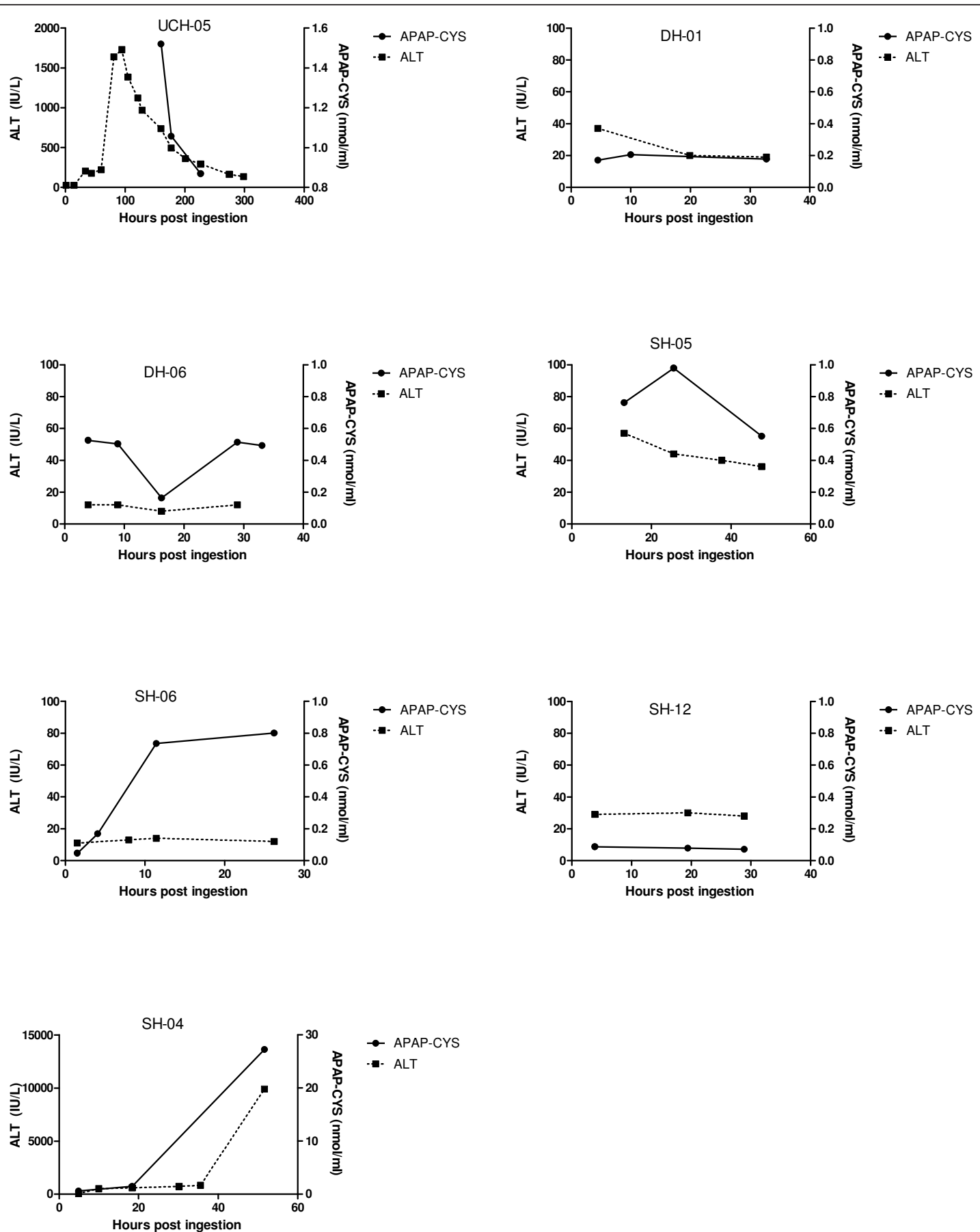

Figure 3 Serum APAP-CYS concentrations and ALT activity for seven patients who received acetylcysteine treatment within 8 hours of their acute acetaminophen overdose. Clinical characteristics of the cases are shown in Table 2. Note that the scale of the axes are different for subject $\mathrm{SH}-04$ to reflect in the range of values for this subject.

similar to the compliance reported for Trial $1(<1 \%$ of doses missed for both studies) and the six Trial 2 subjects with undetectable adduct concentrations did not report any missed doses. An alternative hypothesis is that ethanol exposure may have altered adduct formation. As ethanol is a known inhibitor of CYP 2E1, the enzyme primarily responsible for the formation of NAPQI with therapeutic doses of acetaminophen, it is possible that ethanol blocked NAPQI formation in the group allowed to consume ethanol during the study while the other two groups were not allowed to drink and thus had more metabolism of acetaminophen via 

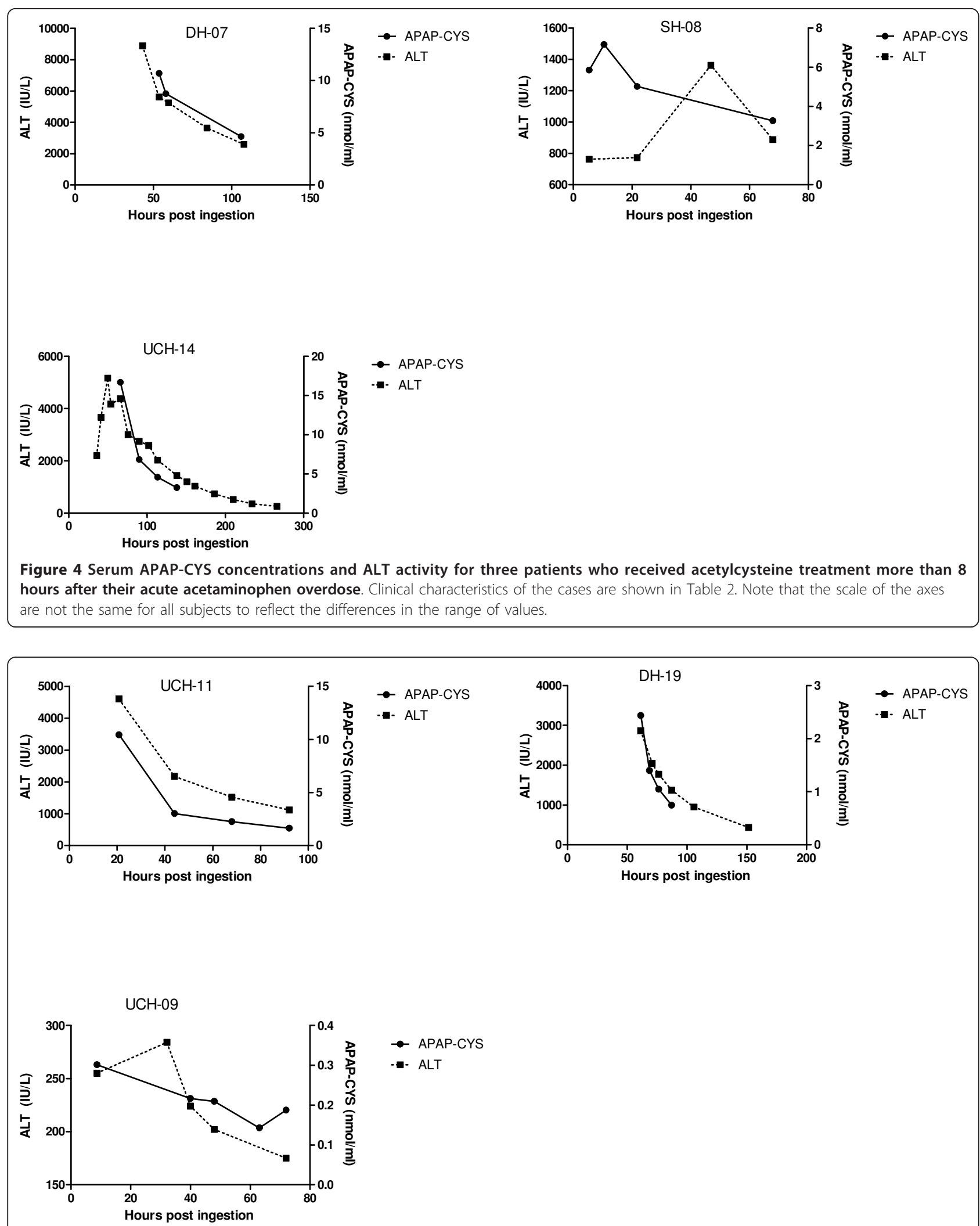

Figure 5 Serum APAP-CYS concentrations and ALT activity for three patients who were treated with acetylcysteine for hepatic injury following repeated supratherapeutic ingestion of acetaminophen. Clinical characteristics of the cases are shown in Table 2. Note that the scale of the axes are not the same for all subjects to reflect the differences in the range of values. 


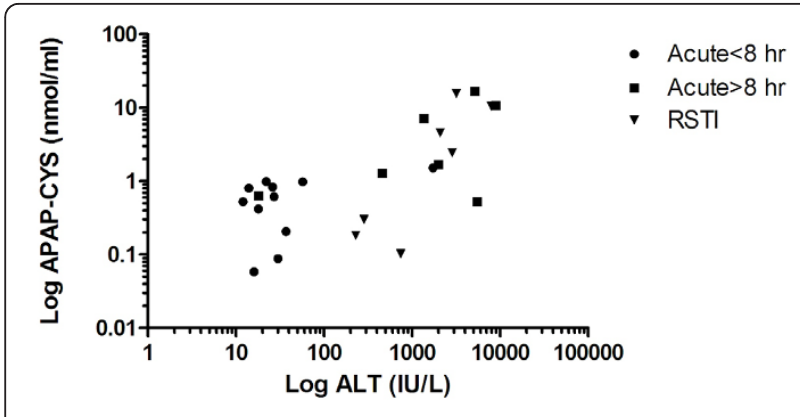

Figure 6 Peak APAP-CYS concentrations plotted by peak ALT for patients treated within 8 hours of acute overdose, for patients treated more than 8 hours after acute overdose and patients treated for repeated supratherapeutic ingestion (RSTI).

CYP 2E1 to NAPQI This mechanism could be further investigated in future large prospective study that compared different ethanol exposures concurrent with APAP exposure and a single sampling scheme.

As no patients who ingested non-acetaminophen hepatotoxins had detectable serum APAP-CYS, our findings support prior publications suggesting that the serum APAP-CYS is specific for APAP exposure in overdose patients [4,12]. Our findings are limited as we only had 4 patients non-acetaminophen patients. In addition, most patients who received early treatment with NAC (Figure 3), had lower adduct concentrations than those that had late treatment with NAC (Figure 4). An exception to this generalization is patient $\mathrm{SH}-04$ (Figure 3). This patient had a low ALT and APAP-CYS concentration at presentation but went on to develop a marked ALT elevation and high APAP-CYS concentration consistent with acetaminophen-induced liver injury. The placebo subjects who had APAP-CYS detected at the end of treatment during the therapeutic trials had measurable concentrations prior to starting the trial and the concentration decreased during the trial. We believe this finding to be consistent with acetaminophen ingestion prior to the trial.

A serum APAP-CYS concentration greater than $1.1 \mathrm{nmol} / \mathrm{ml}$ has a sensitivity of $97 \%$ for identification of patients with hepatotoxicity (defined as an ALT values of $>1000 \mathrm{IU} / \mathrm{L}$ ) when applied to a cohort of patients with acetaminophen overdose [6]. While the mean concentrations in our three therapeutic trials were well below this threshold, one patient in Trial 1 had a peak recorded APAP-CYS concentration of $1.0 \mathrm{nmol} / \mathrm{ml}$ and another patient in Trial 3 had a concentration of $0.8 \mathrm{nmol} / \mathrm{ml}$. Further studies are required to determine if the high sensitivity of this assay threshold is maintained when applied to populations other than acetaminophen overdoses (i.e. therapeutic dosing).

During therapeutic trials, APAP-CYS concentrations increased during the dosing period. It is unknown whether a plateau occurs at some point or whether concentrations continue to rise as long as acetaminophen is consumed. In overdose cases, APAP-CYS concentrations generally decreased following the peak in late presenters and patients with repeated ingestions; the rate of decline closely follows that of ALT and AST. This is consistent with previous reports [6]. The concentrations showed a less consistent decrease in the acute presentations who were treated early.

We found no relationship between APAP-CYS concentrations and serum ALT activity (a commonly used marker of liver injury) in the three trials of therapeutic exposure. One interpretation of this lack of correlation is that low-level adduct formation is not a marker of liver injury. However, it is also possible that there is low level liver injury that is not reflected by changes in transaminases. At this time we cannot make conclusions regarding the lack of correlation between APAP-CYS and ALT. The correlation between APAP-CYS and ALT observed in the overdose cohort was statistically significant and similar to other reports $[6,14]$. For example, a correlation of 0.84 [14] and 0.73 [6] for ALT were previously reported in children and adults, respectively, with APAP overdose. Importantly, the highest concentrations of APAP adducts measured in patients were generally seen in those with severe cases of APAP overdose who did not receive timely treatment with NAC.

\section{Conclusion}

Our findings support previous studies suggesting APAPCYS is a specific marker of acetaminophen exposure, and that adduct concentrations vary according to the degree of exposure. Higher concentrations are associated with liver injury and APAP-CYS was detectable in acetaminophen overdose patients. Currently, an absolute adduct level exceeding $1.1 \mathrm{nmol} / \mathrm{mL}$ appears consistent with acetaminophen toxicity while therapeutic dosing generally produces concentrations below $0.5 \mathrm{nmol} / \mathrm{mL}$. Clinical history, including the magnitude of the exposure, the timing of acetylcysteine administration, and laboratory markers of liver injury should also be taken into account when interpreting adduct concentrations in the lower range. A recent publication has described the use of APAP-CYS to identify occult acetaminophen poisoning among patenits with liver failure of unclear etiology [15]. It is likely that APAP-CYS will be a useful diagnostic test in cases in which the history and standard laboratory testing are not sufficient to establish acetaminophen as a cause of liver injury

There are other potential applications that should be investigated in future studies. We had one patient $(\mathrm{D}=$ 05) who was stratified as high risk (using the nomogram) but who had low adduct concentrations and who did not develop liver injury. While this is a single case, 
it suggests that a low APAP-CYS in high risk patient may be a marker that could be used to identify patients who do not need prolonged therapy. In our small cohort, we found that APAP-CYS concentrations were elevated in all patients who developed hepatoxicity (ALT >1000 IU/L) following repeated ingestions. This suggests that APAP-CYS may be useful for risk stratification following repeated overdose.

\section{Acknowledgements}

This work was supported by the National Institutes of Health National Institute of Diabetes and Digestive and Kidney Diseases [Grants DK06799, DK58639] to Dr. James and by The National Institute on Drug Abuse [Grant DA 020573] to Dr. Heard. We would like to thank the medical toxicology fellows and research division of the Rocky Mountain Poison and Drug Center for their assistance with this project.

\section{Author details}

'Rocky Mountain Poison and Drug Center, Denver Health, Denver CO, USA. 'University of Colorado Department of Emergency Medicine, Aurora CO, USA. ${ }^{3}$ Vanderbilt University School of Nursing, Nashville TN, USA. ${ }^{4}$ Section of Pediatric Pharmacology and Toxicology, Arkansas Children's Hospital Little Rock, AR, USA. ${ }^{5}$ Department of Emergency Medicine, Michigan State University College of Human Medicine, Spectrum Health-Toxicology Services, Grand Rapids, MI, USA. ${ }^{6}$ Department of Emergency Medicine, Division of Medical Toxicology, University of Massachusetts Medical School, Worcester, MA, USA.

\section{Authors' contributions}

$\mathrm{KH}, J \mathrm{G}, \mathrm{RCD}$ designed the study and secured funding. $\mathrm{KH}, \mathrm{JG}, \mathrm{RCD}, \mathrm{BJ}, \mathrm{SR}$ collected the data. $\sqcup$ performed the APAP-CYS determinations. KH and LZ performed the statistical analysis. KH, SR and JG drafted the manuscript and all authors contributed substantially to the revisions and reviewed the final manuscript.

\section{Competing interests}

This study was funded by an investigator-initiated research grant from McNeil Consumer Healthcare to Denver Health. The sponsor had no role in the design, performance, and analysis. The sponsor reviewed the paper for prior to publication, but the authors retained final responsibility for the manuscript. Dr. James has a patent for technology relating to the measurement of acetaminophen protein adducts.

Received: 25 October 2010 Accepted: 14 March 2011 Published: 14 March 2011

\section{References}

1. Hinson JA, Reid AB, McCullough SS, James LP: Acetaminophen-induced hepatotoxicity: role of metabolic activation, reactive oxygen/nitrogen species, and mitochondrial permeability transition. Drug Metab Rev 2004, 36(3-4):805-822.

2. Pumford NR, Hinson JA, Potter DW, Rowland KL, Benson RW, Roberts DW: Immunochemical quantitation of 3-(cystein-S-yl)acetaminophen adducts in serum and liver proteins of acetaminophen-treated mice. J Pharmacol Exp Ther 1989, 248(1):190-196.

3. Roberts DW, Bucci TJ, Benson RW, Warbritton AR, McRae TA, Pumford NR, Hinson JA: Immunohistochemical localization and quantification of the 3-(cystein-S-yl)-acetaminophen protein adduct in acetaminophen hepatotoxicity. Am J Pathol 1991, 138(2):359-371.

4. Davern TJ, James LP, Hinson JA, Polson J, Larson AM, Fontana RJ, Lalani E, Munoz S, Shakil AO, Lee WM: Measurement of serum acetaminophenprotein adducts in patients with acute liver failure. Gastroenterology 2006, 130(3):687-694.

5. James LP, Alonso EM, Hynan LS, Hinson JA, Davern TJ, Lee WM, Squires RH: Detection of acetaminophen protein adducts in children with acute liver failure of indeterminate cause. Pediatrics 2006, 118(3):e676-681.
6. James LP, Letzig L, Simpson PM, Capparelli E, Roberts DW, Hinson JA, Davern TJ, Lee WM: Pharmacokinetics of acetaminophen-protein adducts in adults with acetaminophen overdose and acute liver failure. Drug Metab Dispos 2009, 37(8):1779-1784.

7. James LP, Wilson JT, Simar R, Farrar HC, Kearns GL, Simpson PM, Hinson JA, Pumford NR: Evaluation of occult acetaminophen hepatotoxicity in hospitalized children receiving acetaminophen. Pediatric Pharmacology Research Unit Network. Clin Pediatr (Phila) 2001, 40(5):243-248.

8. Heard KJ, Green JL, Dart RC: Serum alanine aminotransferase elevation during 10 days of acetaminophen use in nondrinkers. Pharmacotherapy 2010, 30(8):818-822.

9. Heard K, Green JL, Bailey JE, Bogdan GM, Dart RC: A randomized trial to determine the change in alanine aminotransferase during 10 days of paracetamol (acetaminophen) administration in subjects who consume moderate amounts of alcohol. Aliment Pharmacol Ther 2007, 26(2):283-290.

10. Dart RC, Green JL, Kuffner EK, Heard K, Sproule B, Brands B: The effects of paracetamol (acetaminophen) on hepatic tests in patients who chronically abuse alcohol - a randomized study. Aliment Pharmacol Ther 2010, 32(3):478-486.

11. James $L$, Simpson P, Rahman S, Russo M, Watkins P: Detection of acetaminophen protein adducts in serum during therapeutic dosing of acetaminophen in healthy volunteers (ABSTRACT). Hepatology 2007, 46(S1):812A

12. James LP, Farrar HC, Sullivan JE, Givens TG, Kearns GL, Wasserman GS, Walson PD, Hinson JA, Pumford NR: Measurement of acetaminophenprotein adducts in children and adolescents with acetaminophen overdoses. J Clin Pharmacol 2001, 41(8):846-851.

13. Muldrew $K L$, James LP, Coop L, McCullough SS, Hendrickson HP, Hinson JA, Mayeux PR: Determination of acetaminophen-protein adducts in mouse liver and serum and human serum after hepatotoxic doses of acetaminophen using high-performance liquid chromatography with electrochemical detection. Drug Metab Dispos 2002, 30(4):446-451.

14. James LP, Capparelli EV, Simpson PM, Letzig L, Roberts D, Hinson JA, Kearns GL, Blumer JL, Sullivan JE: Acetaminophen-associated hepatic injury: evaluation of acetaminophen protein adducts in children and adolescents with acetaminophen overdose. Clin Pharmacol Ther 2008, 84(6):684-690.

15. Khandelwal N, James LP, Sanders C, Larson AM, Lee WM: Unrecognized acetaminophen toxicity as a cause of indeterminate acute liver failure. Hepatology 2010

\section{Pre-publication history}

The pre-publication history for this paper can be accessed here: http://www.biomedcentral.com/1471-230X/11/20/prepub

\section{doi:10.1186/1471-230X-11-20}

Cite this article as: Heard et al:: Acetaminophen-cysteine adducts during therapeutic dosing and following overdose. BMC Gastroenterology 2011 11:20.

\section{Submit your next manuscript to BioMed Central and take full advantage of:}

- Convenient online submission

- Thorough peer review

- No space constraints or color figure charges

- Immediate publication on acceptance

- Inclusion in PubMed, CAS, Scopus and Google Scholar

- Research which is freely available for redistribution

Submit your manuscript at www.biomedcentral.com/submit
C Biomed Central 